\author{
Military Technical College \\ Kobry Elkobbah, Cairo,
}

Egypt.

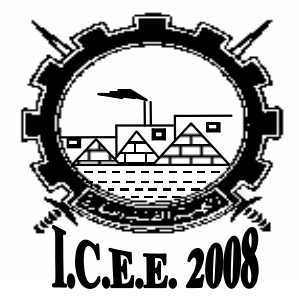

$4^{\text {th }}$ International Conference

On

Chemical \& Environmental

Engineering

27-29 May 2008

\title{
ZINC OXIDE THIN FILM NANO STRUCTURED CATALYSTS PREPARED VIA METAL EVAPORATION AND SOL-GEL TECHNIQUES AS PHOTOCATALYSTS FOR 2,4,6- TRICHLORPHENOL IN WATER
}

\author{
A. K. Aboul-Gheit ${ }^{a}$, Sawsan A. Mahmoud ${ }^{a}$ and A. Abdel Aal ${ }^{\text {b }}$
}

\section{ABSTRACT:}

Two photocatalyst composed of $\mathrm{ZnO}$ in the form of thin film adhered to a glass sheet but prepared using different coating techniques, i.e., metal evaporation ( $M . E_{V}$ ) and sol-gel technique, have been examined for the photodegradation of 2,4,6Trichlorophenol (TCP) in water in presence of UV irradiation at a wave length of 254 $\mathrm{nm}$ in the reactor was constructed of silica glass and air was continuously injected in the pollutant solution while continuous stirring. The concentration of TCP and its intermediate products was determined by HPLC at definite irradiation times. Simple first order kinetics was applied to the change of concentration of TCP as well as the $\mathrm{CO}_{2}$ evolved. Nevertheless, correlation of the types and concentrations of all intermediate products. In TCP degradation on the M.E $\mathrm{E}_{\vee}$ photocatalyst, decay with irradiation time gives complete disappearance of the intermediates after $60 \mathrm{~min}$, whereas used the sol-gel catalyst, all intermediate products are either increase or even increase then remain unchanged as a function of irradiation time. Even though, the difference between the degradation rate of the initial pollutant (TCP) on the two current catalysts is not such great. The adsorption capacity (in dark) of TCP on the ME.v. catalyst was found to be fast at initial time, whereas it is gradual in case of the sol-gel catalyst. This fast adsorption can contribute to the higher activity of the ME.v. catalyst.

\section{KEY WORDS:}

sol -gel, Metal Evaporation , 2,4, 6-Trichlorophenol, photodegradation.

\footnotetext{
a Process Development Division, Egyptian Research Institute, Nasr City, PO Box 9540, Cairo 11787, Egypt,

b Surface Protection\&Corrosion Control Lab, Central Metallurgical Research \& Development Institute (CMRDI),P.O. 87 Hellwan, Cairo, Egypt
} 


\section{INTRODUCTION}

Phenols and chlorinated phenols are widespread pollutants of waste and natural waters [1-4]. Of special note are pentachlorophenol (PCP) and trichlorophenols (2,4,5-TCP, 2,4,6- TCP) [5-8]. Apart from their own biological activity, these pollutants can be highly toxic, as they contain micro impurities of polychlorinated dibenzodioxines (PCDD) dibenzofurans (PCDF) which are the most toxic of xenobiotics [9-14]. Besides, once in the environment, chlorophenols can be transformed into more toxic compounds under the action of natural factors[15-17].

Alternatively to the traditional water treatments, advanced oxidation processes (AOP) represent a promising approach to degrade organic pollutants, transforming them into non-toxic or less toxic products [18]. Heterogeneous photocatalysis performed with irradiated semiconductor dispersions [19-25] is one of the more interesting AOP treatments since it is able in most cases to completely mineralize the organic harmful species.

It has proved that this process can completely destroy many toxic organic compounds in waste water into carbon dioxide [26-28]. The overall process can be summarized by the following reaction :

Organic pollutants $+\mathrm{O}_{2} \rightarrow \mathrm{CO}_{2}+\mathrm{H}_{2} \mathrm{O}+$ mineral acid

$\mathrm{ZnO}$ is a semiconductor which has the same band gap energy of $\mathrm{TiO}_{2}(3.2 \mathrm{ev})$ and similar electronic properties, but it has llimited applications as a photocatalyst for the oxidative degradation purpose due to its photocorrosion. Recently, there has been a growing interest in ultra particles of $\mathrm{ZnO}$ [ 29-34] for efficient photoconversion applications owing to its high surface reactivity. Photocatalytic degradation of cellulose bleaching effluent and kraft black liquor have been widly investigated [3537] using $\mathrm{ZnO}$ catalyst; it was found that $\mathrm{ZnO}$ has activity almost comparable with that of $\mathrm{TiO}_{2}$. Therefore, it seems interesting to investigate the performance of this photocatalyst alternatively to $\mathrm{TiO}_{2}$. Thin film of nanostructured [38-41] $\mathrm{ZnO}$ particles have been used for its high conversion efficiencies in various applications. Most of the studies related to photodegradation reactions have been carried out using suspensions of powdered $\mathrm{ZnO}$ in aqueous solutions. However, their removal from water is difficult and recent research has focused on the preparation of highly photoactive immobilized catalysts for water treatment.

In the present work, we have paid much attention in preparing thin films of of $\mathrm{ZnO}$ on glass plates by a sol-gel process and Metal Evaporation technique. The photocatalytic activities of These prepared catalysts have been compared for the degradation of 2,4,6-TCP. Also the production of chloride ion and the photo intermediate products in water have been studied.

\section{2- Experimental:}

2.1.Preparation of $\mathrm{ZnO}$ Thin film catalysts:

2.1.a. Preparation of $\mathrm{ZnO}$ thin film catalyst using Thermal Evaporation method:

A thin film of $\mathrm{Zn}$ was thermally grown onto a glass substrate under vacuum of $10^{-5}$ torr, using multipurpose vacuum station (sputtering unit) VUP-5M. The growth rate 
and thickness were measured during growth using a crystal oscillator thickness monitor. The growth rate was adjusted to be as low as $10 \mathrm{~nm} / \mathrm{second}$ to avoid the differential evaporation of elements constituting the film. The thermal oxidation process of $\mathrm{Zn}$ films using Naber therm Furnace was carried out at various temperatures $(350-550 \circ \mathrm{C})$ in order to grow thin zinc oxide films on the glass substrate. Zn metal with high purity $(99.9 \%)$ was used as a target.

\section{1.b. Preparation of ZnO thin film catalyst using Sol-Gel method:}

Zinc acetate was dissolved in 2-propanol under vigorous stirring at $50-60^{\circ} \mathrm{C}$. Similarly sodium hydroxide was dissolved in 2-propanol at the same temperature under constant stirring. The zinc acetate-isopropanol solution was kept at $0{ }^{\circ} \mathrm{C}$, then $\mathrm{NaOH}$ solution was added quickly under continuous stirring.

The mixture was kept in water bath for sometime.

The zinc oxide colloid was quite stable and no precipitate was observed. To prepare the film from this colloidal $\mathrm{ZnO}$ sol, glass plates of size $2 \times 3 \mathrm{~cm}$ were dipped in the colloid slowly

then taken out with the same speed and dried in air. This

process was repeated six times. These films were finally calcined at $400{ }^{\circ} \mathrm{C}$ for 2 hours. The $\mathrm{ZnO}$ films, thus obtained was uniform and strongly adherent to the glass sheet.

\subsection{Characterization of the prepared ZnO thin film}

\section{2.a. scanning electron microscop:}

The surface morphology of $\mathrm{ZnO}$ films was studied using a scanning electron microscope (JEOL-JSM- 5410).

\section{2.b. X-ray diffraction :}

A Brucker D8-advance X-ray diffractometer with $\mathrm{Cu} \mathrm{K}_{\alpha}$ radiation $(\lambda=1.5418 \AA$ ) was used.

\section{RESULTS AND DISCUSSION}

Evidently, chlorine ion concentration in the irradiated water is significantly lower on using the catalyst prepared by metal evaporation than on using the catalyst prepared by the sol-gel method (Fig.1). On the former catalyst, $\mathrm{C} \mathrm{I}^{-}$evolution is around $5 \mathrm{ppm}$ during the whole irradiation run, whereas it is around $14 \mathrm{ppm}$ on using the latter catalyst. This behavior may indicate that $\mathrm{Cl}^{-}$evolution in large quantity on a catalyst may have caused a larger opportunity for this catalyst to inhibit further reactions of the adsorbed molecules, i.e., $\mathrm{Cl}^{-}$poisoning occurs. 
SEM photographs taken for the M.evap. catalyst show that the particles are mostly in the form of needles (Fig.2), whereas the sol-gel catalyst particles are in the form of fragmental structure (Fig.3), which may indicate that the ability of the former catalyst to absorb TCP from the polluted water exceeds that of the latter catalyst. Fig.4 shows the adsorption of TCP on the ZnO films prepared by M.evap. and sol-gel methods. This adsorption has been carried out in dark in order to exclude photodegradative possibility .Using the M.evap. catalyst, adsorption of TCP is fast during the first 15 min, beyond which adsoption remains unchanged till $60 \mathrm{~min}$, whereas on the sol-gel catalyst adsorption of TCP is gradual till $60 \mathrm{~min}$ period. The fast adsorption on the M.evap. catalyst implies that the $\mathrm{ZnO}$ catalyst is in the form of nano-tubes.

\section{Photocatalytic degradation of TCP using catalysts prepared via Metal- Evaporation and sol-gel methods:}

Fig. 5 shows that the thin film photocatalyst prepare via M.evap. is more active than the sol-gel prepared catalyst for TCP removal. Using the former catalyst, TCP remaining after $60 \mathrm{~min}$ of irradiation amounts to $4.6 \mathrm{ppm}$ out of $100 \mathrm{ppm}$, whereas using the latter catalyst, TCP remaining amounts to $19.3 \mathrm{ppm}$. Fig. 6 is a first order plot of the photodegradation of TCP using the two current catalysts, where in Ln (a-x) vs. irradiation time plot gives straight lines with good accuracy,i.e., $R^{2}=0.9727$ and 0.9279 respectively. The reaction rate constant $\left(\mathrm{k}_{\mathrm{TCP}}\right)$ for this reaction on these catalysts are 0.0455 and $0.0272 \mathrm{~min}^{-1}$, respectively. Roughly speaking, the M.evap. catalyst is twice more active than the sol-gel catalyst.

Again, the TCP mineralization rate constants $\left(k_{\min }\right)$ or the $\mathrm{CO}_{2}$ evolution ( formation ) rate constant $\left(\mathrm{k}_{\mathrm{CO} 2}\right)$ has been calculated via applying the data in Fig.7. These plots (Fig.7) are straight lines with high accuracy $\mathrm{R}^{2}=0.9727,0.9634$, respectively, giving $\mathrm{k}_{\mathrm{CO} 2}$ values of $0.0723,0.0144 \mathrm{~min}^{-1}$, respectively. For comparison of photodegradation in absence of a catalyst (photolysis), the photodegradation rate constant, $\mathrm{k}$ of TCP is $0.0114 \mathrm{~min}^{-1}$, whereas the $\mathrm{k}$ value for its mineralization $\left(\mathrm{CO}_{2}\right.$ production) is $0.00770 \mathrm{~min}^{-1}$.

\section{Photocatalytic intermediates of TCP}

The majority of intermediates in the photocatalytic degradation of TCP using the two current versions of $\mathrm{ZnO}$ thin film catalysts are aromatic compounds; a part of which contains $\mathrm{C} \mathrm{I}^{-}$or $\mathrm{OH}^{-}$or both, whereas the other part contains quinonic functional groups. The fundamental difference between the activities of M.Ev. and the sol-gel catalysts is evident in comparing figures 8 and 9, respectively. In Fig. 8, it is evident that the intermediates are all up-shooting rapidly to reach a maximum then decline gradually with further increasing the irradiation time. The most important accomplishment on this M.Ev. catalyst is that all intermediates completely disappear at $60 \mathrm{~min}$. Nevertheless, the intermediates formed on the sol-gel catalyst increase progreasively as a function of irradiation time, with no sign of decrease beyond 60 min of irradiation. This indicates that the ring rupture efficiency of this catalyst is markedly weaker than that possessed by the M.Ev. catalyst. 
Both catalysts under investigation are crystalline $\mathrm{ZnO}$; moreover, both are thin films coating glass sheets. Even though, their catalytic activities are markedly different. These differences are evidently exhibited in the SEM photographs. The nanocrystalline thin rods or tubes in the M.Ev. catalyst appear advantageous over the fractured plate-like structures of the sol-gel thin film. The structure of the M.Ev. catalyst have evidently facilitated its adsorptive-absorptive capacity which can be considered as the most effective parameter distinguishing this catalyst.

Fig. 8 shows that the major intermediate is the aromatic trichlorodihydroxybenzene (compound II) (see scheme 1). It reaches as high as $15.5 \mathrm{ppm}$ after $4 \mathrm{~min}$ of irradiation then actively declines with increasing the time till disappears completely at 60 min. This compound forms via attacking a Para carbon of the aromatic ring with an active $\mathrm{OH}$ radical. Simultaneously with the formation of compound (II) dihydroxytrichlorobenzene, dichlorodihydroxybenzene and dichlorotrihydroxybenzene (IV) are formed in modest quantities and reach maxima of 4.0 and $3.0 \mathrm{ppm}$, respectively at $6 \mathrm{~min}$, beyond which they decrease continually till disappear at 60 $\min$.
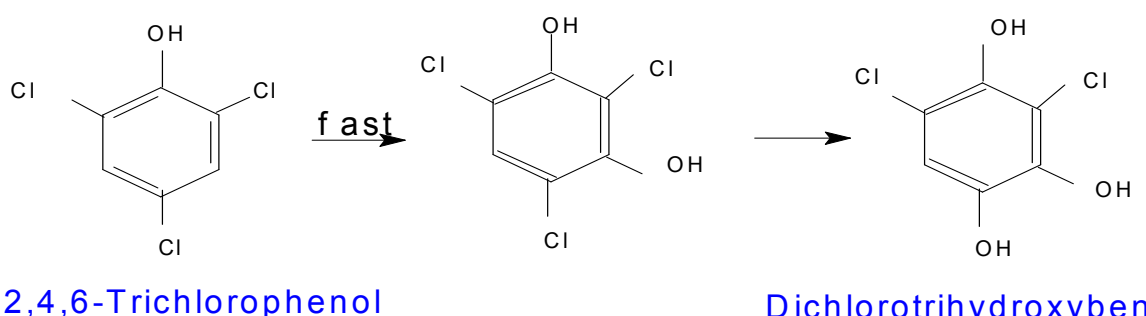

2,4,6-Trichlorophenol

Dichlorotrihydroxybenzene

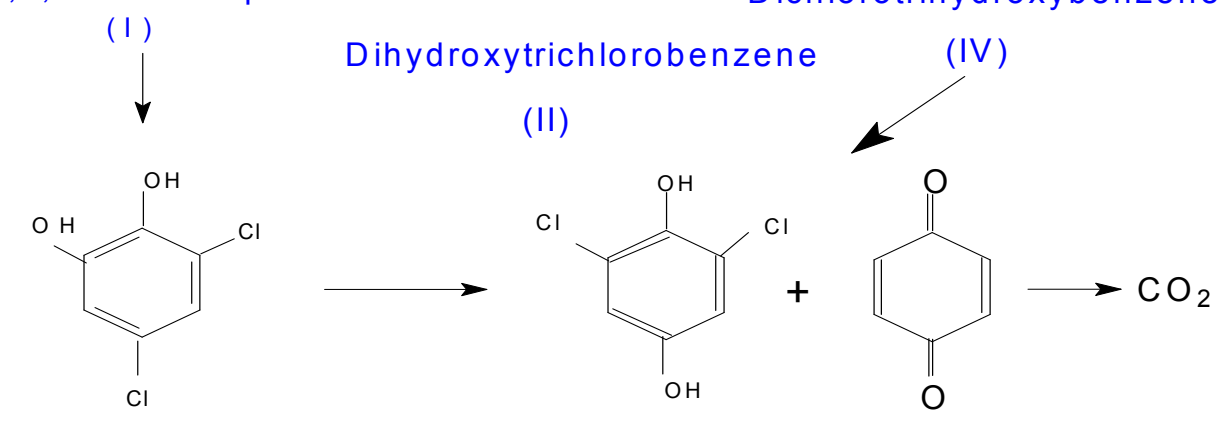

3,5-Dichlorocatchol

(III)

\section{SCHEME 1}

At 20 min of irradiation, hydroquinone starts with a maximum of $6.1 \mathrm{ppm}$ then decline with increasing the time. A small quantity compound with a maximum of $2.5 \mathrm{ppm}$ (benzoquinone) appears at 35 min then decline continually with irradiation time. The overall end of all these intermediates is their complete removal at 60 min after a series of interconversions from one to another via replacement of a $\mathrm{Cl}^{-}$atom by a $\mathrm{OH}$ radical via attacking a Para carbon of the aromatic ring, or finally oxidizing the ring forming quinone. The low concentrations of hydroquinone and benzoquinone appearing in the irradiated solution can be attributed to their fast formation followed by fast degradation. The large surface area and porosity of this M.Ev. catalyst can be 
greatly assisting assisting the fast $\mathrm{O}_{2}$ spill-over spill over flowing as a part of the air pumped with the solution.

Fig 9 shows a major compound increasing with irradiation time till attaining a concentration of as high as $18.0 \mathrm{ppm}$ at $40 \mathrm{~min}$ beyond which its concentration remains unchanged with a further increase of irradiation time. This intermediate is formed from TCP via dechlorination to dichlorodihydroxybenzene (compound II in cscheme I). Asecond intermediate covering most of the irradiation run (from 10- 60 min) with a concentration of almost $5.0 \mathrm{ppm}$. This compound is most probably chlorocatechol (as indicated by HPLC). A third intermediate appeared with a concentration increasing linearly from the beginning as a function of irradiation time. On this sol-gel catalyst hydroquinone and benzoquinone do not appear as products. However, non of the three intermediates identified exhibited a tendency of declining with increasing the irradiation time, which may explain the lower activity of this sol-gel prepared catalyst. It requires much longer irradiation time to give practical photodegradation of TCP.

\section{CONCLUSION}

In general, thin film coated catalysts are much more active than the powdered versions. However, different preparation techniques of the thin film photocatalysts produce differently structured forms and, hence, different catalytic activities for the degradation of organic pollutants. In the present paper, two methods of preparing $\mathrm{ZnO}$ thin films coated on glass sheets have been performed; one method is physical and carried out via evaporation of purest $\mathrm{Zn}$ metal, whereas the other method (chemical) using a sol gel technique was performed. The physical method produced more active photocatalytic degradation of trichlorphenol in water, which was attributed to the nanostructured tubular and needle like particles obtained. The adsorption capacity and rate of adsorption of TCP by these particles exceed those of the chemically prepared thin film catalyst using the sol-gel technique. 


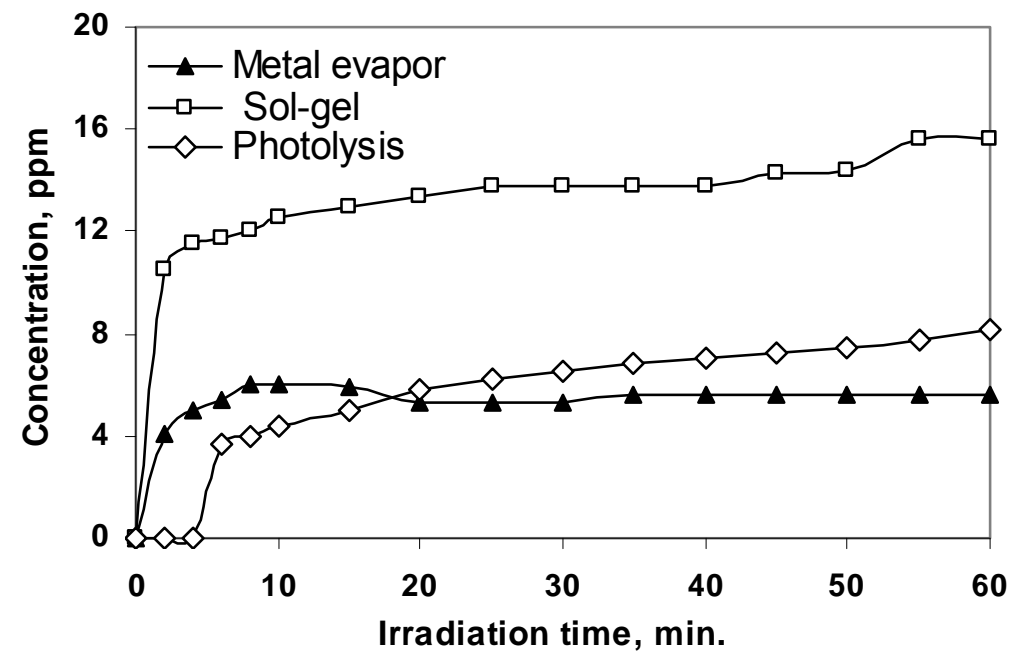

Fig. 1 : Chloride ion in irradiated solution in absence and presence of the Metal evaporation and sol-gel

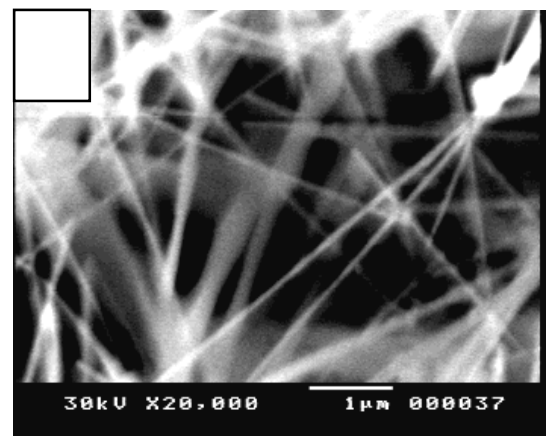

Fig. 2 : SEM photographs for $\mathrm{ZnO}$ prepared $\mathrm{ZnO}$ gel at 550 via Metal $550{ }^{\circ} \mathrm{C}$



Fig. 4 : Ads orption of TCP on ZnO thin film catalysts prepared by thermal evaporation and sol-gel method prepared via prepared via sol${ }^{\circ} \mathrm{C}$ Evaporation at 


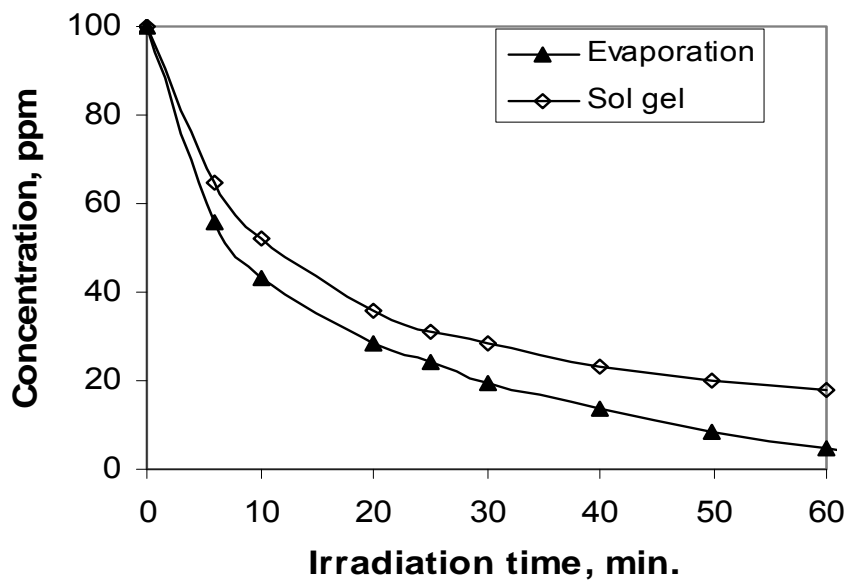

Fig. 5. Photocatalytic decay of TCP using $\mathrm{ZnO}$ catalysts prepared by metal evaporation and Sol-Gel methods.

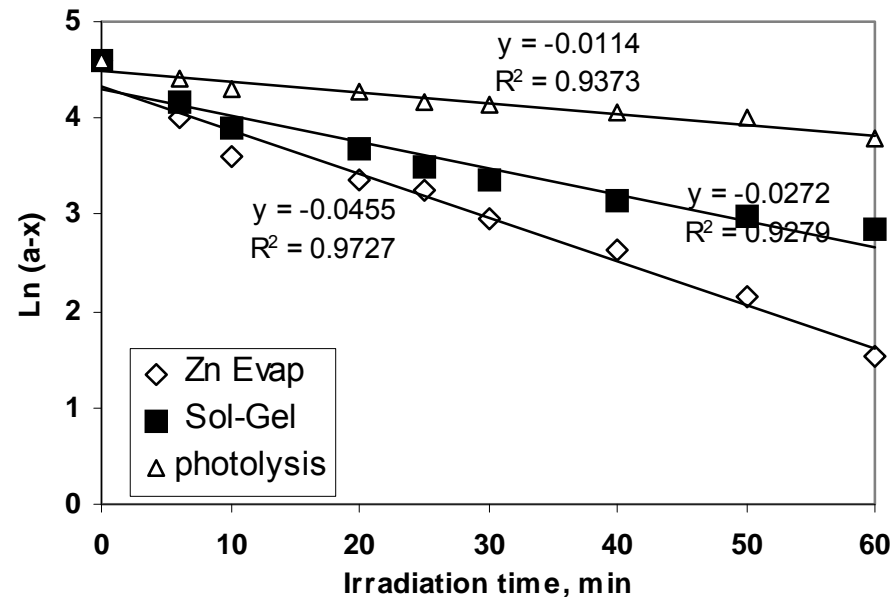

Fig. 6 : TCP photocatalytic degradation first order plot using $\mathrm{ZnO}$ catalysts prepared by Metal Evaporation, sol-gel techniques and photolysis 

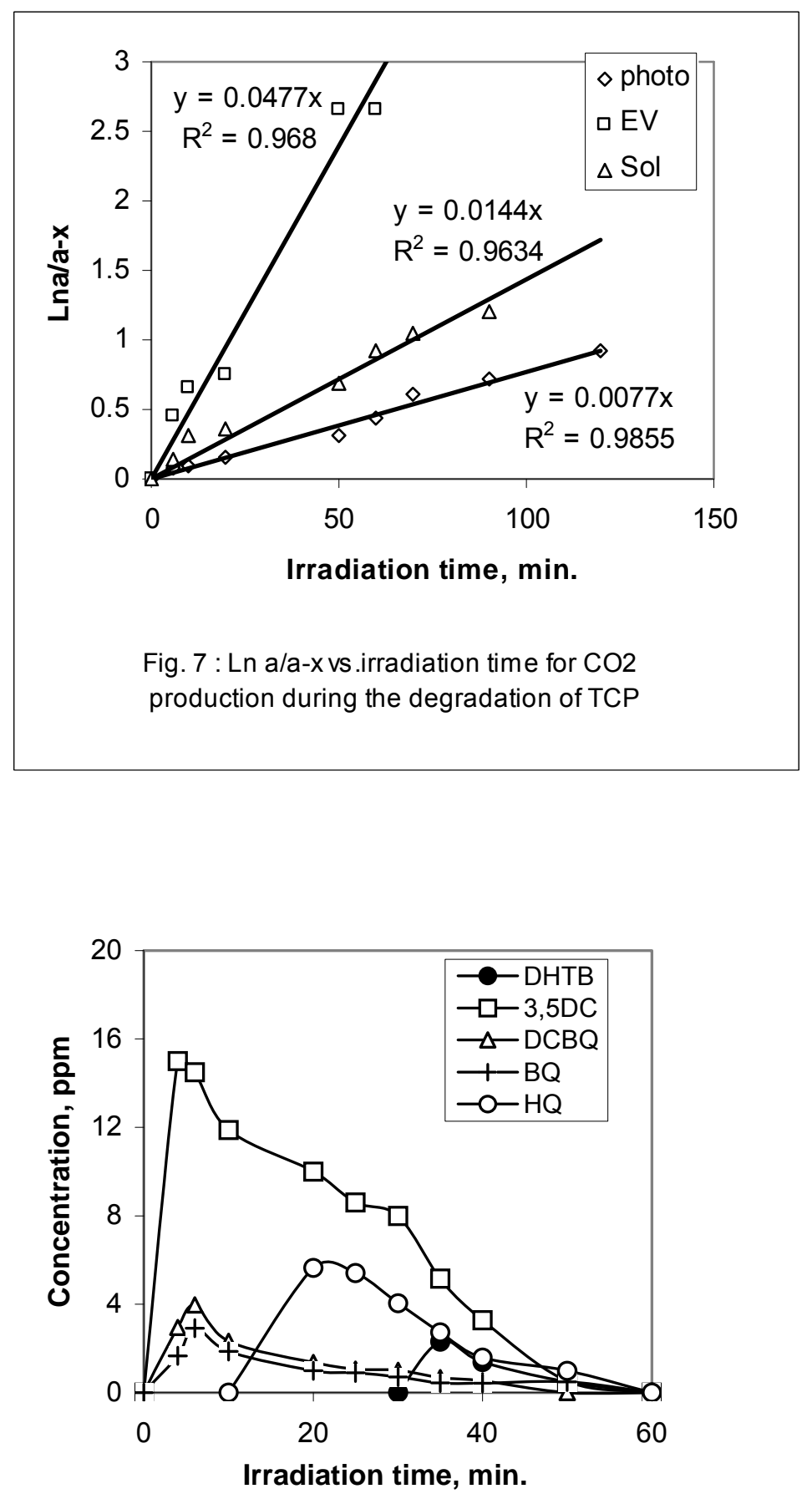

Fig.8: Formation of dihydroxytrichlorobenzene (DHTB), 3,5 dichlorocatecol (3,5DCC), dichlorobenzoquinone (DCBQ), benzoquinone $(\mathrm{BQ})$ and hydroquinone $(\mathrm{HQ})$ during 2,4,6-TCP photodegradation 


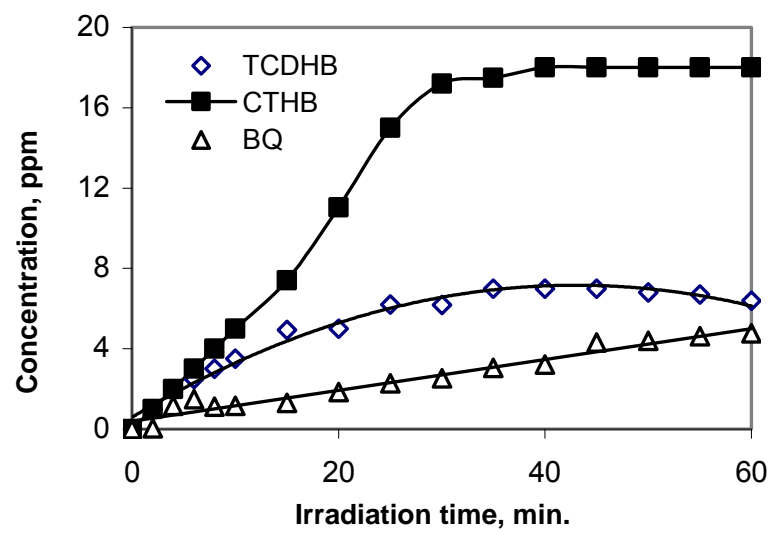

Fig. 9 : Photocatalytic intermediates in water using $\mathrm{ZnO}$ thin film prepared via solgel technique 


\section{REFRENCES:}

[1] G.Dorner Woif, Techn.Resch. 78(1986) 60.

[2] R.Christian, D.Friedrich, K. Paul, Helga, P.Gerhard, S.Manfred, Bonn, Harald Boldt. Verl., 1982, p.168.

[3] J. Paasivitra, Water Sci. Technol.20 (1988) 119.

[4] J. Paasivitra, K. Heinola, T. Humppi, A. Karjalaninen, J.Knuutinen, K.Mantykoski, R.pauuku, T.Piilola, K. Surma-Aho, J.Tarhanen, L.Welling, H. Vihonen, J.Sarkka, Chemosphere 14 (1985) 469.

[5] O. Hutzinger, M.J.Blumich, Chemosphere 14 (1985) 581.

[6] R.Valo, V.Hituuen, M.Salkinuja-Salonen, S.Ralsanen, S.Ralsanen, Chemosphere 13 (1984) 835.

[7] P. Kalliokoski, T . Kauppinen, Complex Mixtures and Cancer Risk, World Health Organ. Int. Agency Res. Cancer.,Lyon, 19990, p.390.

[8] R.Saracel, M.Kogevinas, P.Bertazzl, P.-A. Bertazzl, B.H.B. De Mesquita, D. Coggon, L.M. Green, T.Kauppinen, K.A.L' Abbe, M.Littorin, E.Lynge,

J.D.Mathews, M.Neuberger, J.Osman, N.Pearce, R.Winkelmann, Lancet 8774 (1991) 1027.

[9] C. Rappe, Environ.Sci.Technol.18 (1984) 78A.

[10] W. Christman, K.D. Kloppel, H.Partcht, W. Rotard, Chemosphere 18(1989) 861.

[11] T.V. Rahmanova, D.P. Samsonov, R.I. Pervunina, V.P. Kiryuhin, Agrokhimia 7 (1991) 114 (in Russian).

[12] A.V. Fokin. A.F. Kolomiets, Nature 3 (1985) 3 (in Russan).

[13] IARC Monograph on the Evaluation of the Carcenogenic Risk of chemicals to Man.Some Fumigants, the Herbicides 2,4-D and 2,4,5-T, Chlorinated

Dibenodioxins and Miscellaneous Industerial Chemicals, vol. 15, IARC, WHO, Lyon, 1977, p.354.

[14] O. Hutzinger et at. (Ed.), Chlorinated Dioxins and related compounds. Impact on the Environment., Pergamon, Oxford, 1982, 209 pp.

[15] S.K. Mukerjee, Indian J. Agr. Chem. 18 (1985) 1.

[16] A.Svenso, L.-O. Kjeller, C.Rappe, Environ. Sci. Technol. 23 (1989) 900.

[17] K.C.M. Ree, E.H.G. Evers, M.V.D. Berg, Toxicol.Environ. Chem.23 (1988) 171.

[29] D.W.Bahnemann, C. Kormann, M.R. Hoffman, J. Phys. Chem.91

(1987) 3789.

[30] L. Bhahadur, L. Roy, J.Photochem.Photobiol.A 92 (1995) 207.

[31] T. Schili, P. Boule, J. Lemaire, J. Photochem.Photobiol. A. 50 (1989) 117.

[32] Photobiol.A. C. Richard, F.Bosquet, J.-F. Pilichowski, Photochem.

108 (1997) 45.

[33] L. Spanhel, M. Andrson, J. Am.Chem.Soc. 113 (1991) 2826.

[34] H. Ohnishi, M. Malsamura, H.Tsubomura, M. Iwasaki, Ind. Eng. Chem.Res. 28 (1989) 719.

[35] H.D. Mansilla, J. Villasenor, G. Maturana, J. Baeza, J. Freer, N. Duran, J. Photochem. Photobiol. A 78 (1994) 267.

[36] J. Villasenor, H.D. Mansilla, J. Photochem.Photobiol. A 93 (1996) 205.

[37] C. Richard, J. Photochem.Photobiol. A 72 (1993) 179.

[38] D.Bao, H. Gu, A.Kaung, Thin Solid films 312 (1998) 37.

[39] P. Peralta-Zamora,S.G.de Moraes, R. Pellegrini, M. Freire Jr, H.D. Mansilla, Chemosphere 37 (1998) 2119.

[40] M.C. Yeber, J.Freer, N. Duran, H.D. Mansilla, Chemosphere 41 (2000) 1193.

[41] C. Lee, K. Lim,J. Song,Sol. Energy Mater. Sol. Cells 43 (1996) 37. 